\title{
Research Progress of Anti-breast Cancer Peptides
}

\author{
Zhi-Gang Sun ${ }^{* 1,2}$, Zhi-Na Li ${ }^{1}$, Liang-Hui Zhao ${ }^{3}$, Jin-Mai Zhang ${ }^{4}$ \\ ${ }^{1}$ Central Laboratory, Linyi Central Hospital, No.17 Jiankang Road, Linyi 276400, China \\ ${ }^{2}$ School of Life Sciences, Nanjing University, Nanjing 210023, Jiangsu, China \\ ${ }^{3}$ School of Clinical Medicine, Weifang Medical University, Weifang 261000, Shandong, China \\ ${ }^{4}$ Room 205, BIO-X white house, Shanghai Jiao Tong University, No.1954 Huashan Road, Shanghai 200030,China \\ *Corresponding Author: Zhi-Gang Sun, zhigangsunny@ nju.edu.cn
}

Received 02 August 2019;

Accepted 22 August 2019;

Published 29 August 2019

\begin{abstract}
Breast cancer is a malignant tumor that occurs in the epithelial tissue of the breast, mostly in female. At present, drug resistance has emerged in the treatment of breast cancer. Therefore, the discovery of new drugs for breast cancer is particularly important. Some peptides have been found to have anti-cancer effects. This article reviews the recent discoveries of anti-breast cancer peptides, hoping to provide some help for the development of breast cancer treatment.
\end{abstract}

Keywords: research, breast cancer, peptides, female.

\section{Introduction}

In 2014, about 3.80 million new cancers were diagnosed in China, of which 2.11 million were males and 1.69 million were females, including 0.28 million female breast cancers ${ }^{[1]}$. The estimated new cases of breast cancers in American was 0.27 million, which ranked first in females ${ }^{[2]}$. Beverage alcohol, ionizing radiation and exogenous estrogens are 3 known cause of breast cancer $^{[3]}$. The high incidence of breast cancer in females demonstrates the importance of improving the treatment of breast cancer.

Treatment of breast cancer includes surgery, endocrine therapy, chemotherapy, radiotherapy and molecular targeted therapy. Chemotherapy has become an active treatment for all stages of breast cancer. Most breast cancer is a systemic disease at the time of diagnosis. Systemic chemotherapy can eradicate residual tumor cells in the body, thereby improving the cure rate of surgery. Drug resistance emerged during chemotherapy ${ }^{[4-5]}$. Therefore, the development of new anticancer drugs is of great value for the treatment of breast cancer.

Peptides exhibit many pharmacological activities, such as antimicrobial activity $^{[6]}$, antihypertensive activity $^{[7]}$, antiviral activity $^{[8]}$, and anticancer activity ${ }^{[9]}$. At present, there is no report on the progress of anti-breast cancer peptide. This article will focus on the recent development of anti-breast cancer peptides.

\section{Peptides with anti-breast cancer activities}

Jie $\mathrm{Lu}$ and coworkers found a novel glycine-rich antimicrobial peptide, SK-84, had specific inhibitory effects on the proliferation of the MCF-7 cells $\left(\mathrm{IC}_{50}=50 \mu \mathrm{M}\right)$ in a dose-dependent manner ${ }^{[10]}$.
The weights of two antiproliferative peptides isolated from Protease XXIII (PR) and papain (PA) hydrolysates of tuna dark muscle byproduct were $1124 \mathrm{Da}$ and $1206 \mathrm{Da}$, and they showed inhibitory effect of the MCF-7 cells in dose-dependent manner, with $\mathrm{IC}_{50}$ values of 8.8 and $8.1 \mu \mathrm{M}$, respectively ${ }^{[11]}$.

Eun-Kyung Kima and cowokers obtained the purified anticancer peptide with the weight of about $1950 \mathrm{kd}$ from Ruditapes philippinarum. The amino acid sequence of this peptide was Ala-Val-Leu-Val-Asp-Lys-Gln-Cys-Pro-Asp. Moervoer, the cytotoxicity activity of the peptide was investigated, and the $\mathrm{LC}_{50}$ value was $1.58 \mathrm{mg} / \mathrm{ml}$ on MDA-MB-231 cells ${ }^{[12]}$.

Xiaodan Fan and coworkers identified one new peptide VPGTPKNLDSPR from the Porphyra haitanesis hydrolysate, which displayed good inhibitory effect on MCF-7 cells, with the $\mathrm{IC}_{50}$ value of $200.97 \mu \mathrm{g} / \mathrm{mL}^{[13]}$.

Che Wang and coworkers found L-K6, a lysine/leucine-rich cationic antimicrobial peptide, displayed anticancer activity both in vitro and in vivo. Furthermore, it preferentially to kill cancer cells with much lower toxicity to normal cells by nucleus-targeting mechanism. Specifically, L-K6 partially identifies the surface of cancer cells through PS-related mechanisms and passes through the MCF-7 cell membrane through a clathrin-independent macropinocytosis. Ultimately, L-K6 causes cancer cell death through DNA damage and nuclear targeting without obvious destruction of cell membrane, cytoskeleton and mitochondria ${ }^{[14]}$.

Peptide LLPSY, isolated from olive seeds, was found to have a strong anti-proliferative effect dose-dependent manner in MDAMB-468 cancer cells after $24 \mathrm{~h}$ with the $\mathrm{IC}_{50}$ value of 97.6 $\mu \mathrm{g} / \mathrm{mL}^{[15]}$. 
AFPep, a 9-amino acid cyclic peptide, was found to inhibit the growth of human MCF-7 breast cancer xenografts without affecting the liver growth ${ }^{[16]}$.

Yun-Jeong Jeong and coworkers found that melittin, a small protein with 26 amino acid residues, could inhibit EGF-induced tumor invision via suppressing FAK phosphorylation and MMP-9 expression in breast cancer cells ${ }^{[17]}$.

\section{Conclusion}

The high incidence of breast cancer has increased the burden of young mothers. Family problems caused by breast cancer have more or less harmful effects on children's growth. Therefore, it is necessary to strengthen the prevention of breast cancer. Many studies on the prevention of breast cancer have been studied ${ }^{[18-19]}$.

To sum up, only a few anti-breast cancer peptides have appeared at present. More peptides with anti-breast cancer activity need to be found, so as to provide more options for the treatment of breast cancer. At present, there are two ways to increase anti-breast cancer peptide: 1) through screening natural product peptides, new anti-breast cancer peptide can be obtained; 2) structural modification of the discovered anti-cancer peptide, and then further screen its anti-breast cancer activity.

With the discovery of more pharmaceutical-active peptides, more anti-breast cancer peptides will also be found.

\section{Conflicts of Interest}

The authors declare that there is no conflict of interest regarding the publication of this paper.

\section{Funding Statement}

The article was funded by Health Commision of Shandong Province (No. 2016WS0242).

\section{Acknowledgements}

This work was supported by the Linyi Science and Technology Innovation and Development Project (Medicine) (No. 201818033) and the Project of Medical and Health Science Technology Development Program in Shandong Province of China (No. 2016WS0242)

\section{References}

[1] Chen, W.; Sun, K.; Zheng, R.; Zeng, H.; Zhang, S.; Xia, C.; Yang, Z.; Li, H.; Zou, X.; He, J., Cancer incidence and mortality in China, 2014. Chinese journal of cancer research 2018, 30 (1), 1-12.

[2] Siegel, R. L.; Miller, K. D.; Jemal, A., Cancer statistics, 2019. CA: a cancer journal for clinicians 2019, 69 (1), 7-34.

[3] MacMahon, B., Epidemiology and the causes of breast cancer. International journal of cancer 2006, 118 (10), 2373-2378.

[4] Kovalchuk, O.; Filkowski, J.; Meservy, J.; Ilnytskyy, Y.; Tryndyak, V. P.; Vasyl'F, C.; Pogribny, I. P., Involvement of microRNA-451 in resistance of the MCF-7 breast cancer cells to chemotherapeutic drug doxorubicin. Molecular cancer therapeutics 2008, 7 (7), 2152-2159.
[5] Housman, G.; Byler, S.; Heerboth, S.; Lapinska, K.; Longacre, M.; Snyder, N.; Sarkar, S., Drug resistance in cancer: an overview. Cancers 2014, 6 (3), 1769-1792.

[6] de Melo, E. T.; Estrela, A. B.; Santos, E. C. G.; Machado, P. R. L.; Farias, K. J. S.; Torres, T. M.; Carvalho, E.; Lima, J. P. M. S.; Silva-Júnior, A. A.; Barbosa, E. G., Structural characterization of a novel peptide with antimicrobial activity from the venom gland of the scorpion Tityus stigmurus: Stigmurin. Peptides 2015, 68, 3-10.

[7] Saleh, A. S.; Zhang, Q.; Shen, Q., Recent research in antihypertensive activity of food protein-derived hydrolyzates and peptides. Critical reviews in food science and nutrition 2016, 56 (5), 760-787.

[8] Novoa, B.; Romero, A.; Álvarez, Á. L.; Moreira, R.; Pereiro, P.; Costa, M. M.; Dios, S.; Estepa, A.; Parra, F.; Figueras, A., Antiviral activity of myticin $\mathrm{C}$ peptide from mussel: an ancient defense against herpesviruses. Journal of virology 2016, 90 (17), 7692-7702.

[9] Dia, V. P.; Krishnan, H. B., BG-4, a novel anticancer peptide from bitter gourd (Momordica charantia), promotes apoptosis in human colon cancer cells. Scientific reports 2016, 6, 33532.

[10] Lu, J.; Chen, Z.-w., Isolation, characterization and anticancer activity of SK84, a novel glycine-rich antimicrobial peptide from Drosophila virilis. Peptides 2010, 31 (1), 44-50.

[11] Hsu, K.-C.; Li-Chan, E. C.; Jao, C.-L., Antiproliferative activity of peptides prepared from enzymatic hydrolysates of tuna dark muscle on human breast cancer cell line MCF-7. Food Chemistry 2011, 126 (2), $617-$ 622.

[12] Kim, E.-K.; Kim, Y.-S.; Hwang, J.-W.; Lee, J. S.; Moon, S.-H.; Jeon, B.-T.; Park, P.-J., Purification and characterization of a novel anticancer peptide derived from Ruditapes philippinarum. Process Biochemistry 2013, 48 (7), 1086-1090.

[13] Fan, X.; Bai, L.; Mao, X.; Zhang, X., Novel peptides with anti-proliferation activity from the Porphyra haitanesis hydrolysate. Process Biochemistry 2017, 60, 98-107.

[14] Wang, C.; Dong, S.; Zhang, L.; Zhao, Y.; Huang, L.; Gong, X.; Wang, H.; Shang, D., Cell surface binding, uptaking and anticancer activity of L-K6, a lysine/leucine-rich peptide, on human breast cancer MCF-7 cells. Scientific reports 2017, 7 (1), 8293.

[15] Vásquez-Villanueva, R.; Muñoz-Moreno, L.; Carmena, M. J.; Marina, M. L.; García, M. C., In vitro antitumor and hypotensive activity of peptides from olive seeds. Journal of functional foods 2018, 42, 177-184.

[16] Mansouri, W.; Fordyce, S. B.; Wu, M.; Jones, D.; Cohn, D.; Lin, Q.; Feustel, P.; Sharma, T.; Bennett, J. A.; Andersen, T. T., Efficacy and tolerability of AFPep, a cyclic peptide with anti-breast cancer properties. Toxicology and applied pharmacology 2018, 345, 10-18.

[17] Jeong, Y.-J.; Choi, Y.; Shin, J.-M.; Cho, H.-J.; Kang, J.H.; Park, K.-K.; Choe, J.-Y.; Bae, Y.-S.; Han, S.-M.; Kim, C.-H.; Chang, H.-W.; Chang, Y.-C., Melittin suppresses EGF-induced cell motility and invasion by inhibiting PI3K/Akt/mTOR signaling pathway in breast cancer cells. Food and Chemical Toxicology 2014, 68, 218-225. 
[18] Gulati, G.; Heck, S. L.; Ree, A. H.; Hoffmann, P.; Schulz-Menger, J.; Fagerland, M. W.; Gravdehaug, B.; von Knobelsdorff-Brenkenhoff, F.; Bratland, Å.; Storås, T. H.; Hagve, T.-A.; Røsjø, H.; Steine, K.; Geisler, J.; Omland, T., Prevention of cardiac dysfunction during adjuvant breast cancer therapy (PRADA): a $2 \times 2$ factorial, randomized, placebo-controlled, double-blind clinical trial of candesartan and metoprolol. European Heart Journal 2016, 37 (21), 1671-1680.

[19] Fabian, C. J.; Kimler, B. F.; Hursting, S. D., Omega-3 fatty acids for breast cancer prevention and survivorship. Breast Cancer Research 2015, 17 (1), 62. 